\title{
Centroamericanos en el Soconusco: RESEÑA DE SU PRESENCIA A TRAVÉS DE SUS PARADOJAS
}

\author{
Jaime Rivas Castillo
}

\begin{abstract}
Resumen:Elartículo tiene comoobjetivo destacar lapresenciade los centroamericanos en la región chiapaneca del Soconusco, en México. Sepersigue el objetivo mediante la discusión de dos paradojas, que a su vezcorresponden a la parte medular del texto. La primera se refiere a la situación muy particular de dicharegión: apieentre Centroamérica y México, parece ser la región más "centroamericana" de este país. La segunda compete directamente a los migrantes centroamericanos, en tanto que resultaparadójico cómo estos no aparecenen lasestadísticas oficiales, pese a constituir el contingente poblacional de origen extranjeromás significativo en la región; por el contrario, supresencia es puesta de relieve de un modo indirecto, revisando las estadísticas de extranjeros asegurados y devueltos a sus países de origen. Se trata, pues, de una presencia destacada por su ausencia; mejor dicho, por su expulsión. El trabajo se nutre de dos fuentes principales: revisión bibliográficaeinvestigación de campo realizada en lazona de estudio.
\end{abstract}

Palabras clave: Chiapas. Soconusco. Centroamérica. Proceso migratorio centroamericano. Flujos migratorios.

Enviado a dictamen: 25 de enero de 2010

Aprobación: 15 de abril de 2010

Revisiones: 1

Jaime Rivas Castillo, maestro en Antropología Social por el CIESAS-Sureste, candidato a Doctor en Ciencias Sociales por el CIESAS-Occidente, labora en CIESAS-Sureste. Carr. San Cristóbal-San Juan Chamula, Km. 3.5, Barrio Quinta San Martín, San Cristóbal de Las Casas, Chiapas, México. Temas de especialización: Migración, desarrollo y derechos humanos. Proceso migratorio centroamericano. Correo electrónico: jarrivas@hotmail.com.
Abstract: This article has the aim to underline the presence of Central American people in the chiapanec region called Soconusco, in Mexico. Two paradoxes, which correspond to the core of the article, are analyzed to reach this goal. First, it refers to the particular situation of this region: located between Central America and Mexico, it seems to be the most Central American part of the country. Second, it is related particularly to Central American people, who are not visible in the official statistics, despite being the most remarkable group of foreign people within the region. On the contrary, their presence is relevant through an oblique form, by the numbers of alien people being captured and repatriated to their countries. It is a presence remarked by its absence, or better to say, by their expulsion. This work has been nourished by two sources: bibliography and original fieldwork conducted on this area.

Keywords: Chiapas. Soconusco. Central América. Central American Migration Process. Migration Flows.

\section{Introducción: El Soconusco, un espacio social en disputa}

$\square$ Soconusco es una de las nueve regiones económicas del sureño estado de Chiapas, ubicado en México. Limita al norte con las regiones Frailesca y Sierra; al este, con la República de Guatemala; al sur con el Océano Pacífico y al oeste con 
la región Istmo-Costa (ver Mapa 1). La mayor parte de su territorio se afinca sobre una pequeña franja formada por una llanura costera, delimitada a su vez por la Sierra Madre de Chiapas al norte, y el Océano Pacífico al sur. Lo anterior facilita el papel que juega la región como corredor natural. El Soconusco se compone de dieciséis municipios: Acacoyagua, Acapetahua, Cacahoatán, Escuintla, Frontera Hidalgo, Huehuetán, Huixtla, Mapastepec, Mazatán, Metapa, Suchiate, Tapachula, Tuxtla Chico, Tuzantán, Unión Juárez y Villa Comaltitlán (ver Mapa 2).

Tapachula, la cabecera regional, es la ciudad más importante de la zona en términos demográficos, comerciales, políticos y administrativos. El Censo de Población y Vivienda del año 2000 registra una población de 271,674 habitantes en este municipio, lo que representa 40.9\% del Soconusco; según la misma fuente, $72.1 \%$ de los tapachultecos vive en cuatro localidades urbanas, mientras que el restante $27.9 \%$ de la población reside en 489 localidades rurales. Aunque el municipio describe una importante actividad agrícola, desde los años noventa se ha experimentado un repunte del sector terciario, sobre todo en el comercio y los servicios. La industria local es muy incipiente, siendo el sector terciario el que más pujanza ha descrito durante los últimos tres lustros. Aun así, el aporte del sector agrícola de la región en conjunto sigue siendo significativo: en el año 2000, INEGI reportaba que el Soconusco aportó un poco más de 35\% del valor de la producción agrícola del estado de Chiapas, mientras que el café y el plátano aportaron 52\% del valor de los dos cultivos (Villafuerte, 2008: 163 y 166).

Huixtla es el segundo municipio más importante de la región, de ella estos son los principales indicadores que aquí interesan: con una extensión territorial de 385 kilómetros cuadrados tiene sólo una localidad urbana y 256 rurales; $55.7 \%$ de sus 48,476 habitantes reportados en el año 2000 reside en la localidad urbana y $44.3 \%$ en las localidades rurales; la agricultura es la principal actividad económica. Se produce maíz, frijol, ajonjolí, café, caña de azúcar, cacao, tabaco y plátano, cosechas en las que se emplean muchos centroamericanos. Pese a que la región cuenta con dieciséis municipios, se han mencionado aquí sólo algunos datos de dos de sus principales localidades, para tener una idea de su composición demográfica y las actividades económicas formales en las que se ocupa la gente, entre ella la originaria de Centroamérica.

Por otro lado, Tapachula y su zona de influencia concentra buena parte de las instituciones gubernamentales mexicanas que gestionan la migración en la frontera que México tiene con Centroamérica, justo en una de las entradas de una nación que, como vecina de Estados Unidos, juega un rol fundamental como país de tránsito de migrantes internacionales en situación irregular. Como tal, la región es objeto de la aplicación de políticas de contención - no pocas veces rozando los principios más elementales de derechos humanos- de los flujos de migrantes internacionales que se internan a ella con el objetivo de llegar a la frontera norte mexicana y cruzar hacia Estados Unidos. Como en toda frontera, sobre el Soconusco recae con mayor intensidad el peso de las políticas de Estado que persiguen mantener a su gente dentro de los límites de la nacionalidad - la mexicana, en este caso- - trayendo consigo fuertes presiones en términos de identidad nacional, en aras de distinguir al "nosotros" — los mexicanos - de los "otros" - los extranjeros.

Tomando como referente el fenómeno migratorio, en el Soconusco se hace evidente un juego entre algunos de sus actores que, a manera pendular, se acerca a veces a la legalidad y a ratos se encuentra del lado de la ilegalidad. La disputa, o más bien el juego de lo legal y lo ilegal, empieza desde la línea fronteriza, que es precisamente uno de los símbolos en pugna. Lo que se observa a diario es a decenas de migrantes indocumentados cruzando dicho espacio, burlando a las autoridades, negociando su pase con ellas o simplemente, ante la pasividad de aquellas, pasando a sus espaldas; se observa, en definitiva, una frontera traspasada, desbordada y 
fragmentada, sujeta al ir y venir de los actores sociales. Consecuente con esa realidad, el análisis desarrollado en las siguientes líneas se hace desde una perspectiva teórica centrada en el actor social, que considera a los migrantes centroamericanos - y a los demás actores en interacción - no como meros sujetos pasivos, sino como participantes activos de los procesos sociales en los que se desenvuelven. Se trata de actores que reciben, interpretan e intercambian información; que diseñan estrategias en sus relaciones con otros actores, así como con las instituciones externas; que forcejean, disputan, negocian y transigen no solo en encuentros cara a cara, sino también con los ausentes - otros migrantes situados en otros lugares, por ejemplo- mismos que pueden influir en las situaciones y decisiones, afectando las acciones y sus resultados (Long, 2007: 41). Este último punto es particularmente relevante en todo un cuerpo de conocimiento que enfatiza el protagonismo de la gente en los procesos sociales.

La perspectiva del actor social es afín a la noción de habitus de Bourdieu, introducida por este actor dentro de su teoría de la práctica (Bourdieu, 1997: 8; 1990: 72; Bourdieu y Wacquant, 1995: 79). El sociólogo francés ha querido escapar tanto del objetivismo de la acción, entendida como reacción mecánica a los condicionamientos externos - carente de agente, por lo tanto - como del subjetivismo, el cual describe la acción como la realización deliberada de una intención conciente, como libre propósito de una conciencia que establece sus propios fines y maximiza su utilidad mediante el cálculo racional. De este modo, la práctica de los centroamericanos - lo que hacen en su vida cotidiana - estaría mediada tanto por los constreñimientos estructurales — su nacionalidad, la escasez del empleo, su condición de género, una política migratoria restrictiva, la discriminación, etcétera- como por sus capacidades y su grado de vulnerabilidad. Dicho de otro modo, se tienen ciertas capacidades solo en el marco de un contexto. En este sentido, por ejemplo, los migrantes construyen redes sociales dentro de los márgenes que permite el contexto del Soconusco, donde probablemente ya haya parientes o amigos que les precedieron en el camino y donde hay una estructura montada sobre organismos civiles y religiosos - albergues o casas de migrantes, descansos, centros de derechos humanos, Iglesias- que son potenciales apoyos mientras aquellos atraviesan el territorio soconusquense.

El análisis centrado en el actor social permite identificar, describir y explicar las respuestas diferenciadas de la gente a circunstancias estructurales similares, aun cuando las condiciones parezcan más o menos homogéneas. Al respecto, resulta sumamente interesante cómo los migrantes centroamericanos que se acogen a los programas de regularización migratoria ejecutados por el Instituto Nacional de Migración, INM, confieren diferente significación y utilidad práctica a dichos programas, sirviéndose de ellos y procesándolos de muy diversos modos. A guisa de ejemplo, es sabido que no todos los extranjeros que obtienen su documento migratorio que ampare su estancia legal en el país se quedan realizando las actividades a las que fueron autorizados o permanecen en las localidades en donde recibieron aquellos documentos: muchos los utilizan para transitar legalmente por México y avanzar en su travesía hacia Estados Unidos, retomando un proyecto inicial temporalmente abandonado; otros se quedan en las mismas localidades para lograr una mayor inserción social propia y de su familia; no pocos, finalmente, utilizan su documento migratorio para conseguir un empleo más digno o mejor remunerado en otros sitios.

La perspectiva del actor social permite ver también a las autoridades no solo transigiendo bajo la mesa con los migrantes en aquel juego a lo legal e ilegal, sino también cumpliendo con su papel escrito en la ley. De ahí las cifras de aseguramiento de migrantes indocumentados y todas las acciones orientadas a la contención de los flujos migratorios. La perspectiva conceptual desde la que se observan los fenómenos 
en cuestión, obviamente, sirve como marco general de análisis e interpretación de la información bibliográfica consultada y los datos recabados en el campo, y constituye un posicionamiento teórico y metodológico, en tanto que se persigue una paulatina inmersión en el espacio social construido en el Soconusco por sus diversos actores, pero fundamentalmente a partir de aquellos que han sido invisibilizados por las instituciones gubernamentales mexicanas, salvo cuando se trata de asegurarlos y devolverlos a sus países: los migrantes centroamericanos. Dicha inmersión se realiza a partir de estudios de caso documentados en algunos municipios de la región del Soconusco. Dicho lo anterior llega el momento de introducir a los principales actores sociales considerados en este artículo.

\section{La región "más centroamericana” del estado "más mexicano"l}

La ubicación geográfica del Soconusco — como puente natural entre Chiapas y Centroamérica- y su trayectoria histórica le da a esta región un cariz muy particular dentro del conjunto de las regiones chiapanecas. De ahí que no sea ninguna quimera aludir a la "vocación centroamericana" de Chiapas y de su región más meridional (De Vos, 2002: 52). Pueden traerse a mención diversas razones - geográficas, territoriales, ambientales, históricas, lingüísticas, culturales, sociales y comerciales - en algún momento exploradas por diversos trabajos académicos, pero resulta pertinente aludir acá a un poderoso motivo que podríamos convenir en llamarlo poblacional o demográfico: la presencia de la gente de Centroamérica. Acto seguido se abundará en algunos de los flujos de migrantes centroamericanos presentes en dicha región, pero de momento baste mencionar que el Soconusco, por su condición de frontera, es atravesado por migrantes en tránsito y alberga a centroamericanos que llegan a esta región con la intención de residir y/o trabajar ya sea temporal como definitivamente. Para la gente de
Centroamérica, pues, el Soconusco es tanto una región de tránsito como de destino.

Apelando a viejas discusiones nacionalistas, habría que decir que esta sería la región "más centroamericana" del estado "más mexicano". Aludamos de manera muy sucinta a lo histórico, como punto de partida. El Soconusco, en efecto, declaró su independencia tanto de Guatemala como de Chiapas en 1821, luego quedó en una posición neutral desde 1825 hasta 1842, cuando se convirtió en la última región chiapaneca en anexarse, mediante la fuerza militar, a la nación mexicana. De Vos escribe que "la salida de Chiapa y Soconusco, en 1824, de la confederación centroamericana y su entrada en la República mexicana fue, igual que en 1528, una decisión tomada por unos pocos en nombre de todos los demás" (De Vos, 2005: 17). Dicho proceso histórico político no estuvo exento de conflictos entre las dos naciones que reclamaban como suya esta rica región; de ahí que el Soconusco haya sido también el último pretexto de las disputas territoriales en la región fronteriza. Otro autor lo resume así:

[El Soconusco] a la vez posee una identidad e importancia propias, en la medida en que, como zona de intensa actividad productiva, ha generado beneficios no solo para algunos de sus habitantes, sino también con amplias derramas económicas para el estado de Chiapas y de generación de divisas para la economía nacional. Por otro lado, es la porción fronteriza en la que se han expresado con mayor intensidad las tensiones derivadas de los sentimientos de pertenencia y de las dificultades para la definición de los límites internacionales (Castillo, 2002, p. 35).

Descontada la negociación que terminó con las disputas limítrofes - mas no con algunos resentimientos históricos, sobre todo del lado guatemalteco, ni mucho menos con la conflictividad social que hoy por hoy caracteriza a la región - hay que mirar a su gente, la misma que quedó al margen de las negociaciones 
y acuerdos tomados por unos pocos detrás de sus escritorios.

La presencia en el Soconusco de la gente originaria del conjunto de naciones que hoy conforman Centroamérica ${ }^{2}$ - la muestra más palpable de la "centroamericanización" de Chiapas- es anterior incluso a la formación de los Estados nacionales en México y el Istmo centroamericano. Hay que traer a colación, por ejemplo, el poblamiento de grupos étnicos de raigambre maya que ahora se reparten entre México, Guatemala, Honduras y El Salvador. Los guatemaltecos habrían sido los primeros en desplazarse a la región, aunque no los últimos, con el relativamente reciente incremento de los flujos de migrantes en tránsito de otras nacionalidades que atraviesan esta región con la intención de llegar a Estados Unidos. Si se parte de las cifras de extranjeros "asegurados"3 anualmente por el Instituto Nacional de Migración mexicano, en la actualidad, el grueso de la presencia de centroamericanos en el Soconusco lo conforman guatemaltecos, hondureños y salvadoreños, seguidos de lejos por los nicaragüenses. Buena parte de aquellos, no se sabe en qué magnitud, se han quedado a vivir en la región o transitan en sentido inverso, de norte a sur, en calidad de deportados, sumándose a los flujos de migrantes en tránsito hacia la frontera de México con Estados Unidos.

Se dispone de varias clasificaciones sobre los grupos migratorios de centroamericanos en México, basadas en criterios legales, laborales, tiempo de permanencia y dirección de los flujos, fundamentalmente. Así, la Encuesta sobre Migración en la Frontera Guatemala-México distingue los flujos migratorios por "direccionalidad" - sur-norte, norte-sur-, por "motivo de cruce" laboral, comercial, familiar, turístico, entre otrospor "condición migratoria de cruce" - documentado e indocumentado- y por "destino" - México en sus diversas localidades y Estados Unidos.

Rodolfo Casillas, uno de los estudiosos pioneros sobre el proceso migratorio centroamericano en México identifica, a finales de los años ochenta, cuatro flujos migratorios: a) residentes fronterizos y dispersos en el país, b) trabajadores agrícolas temporales y cotidianos, c) transmigrantes, y d) refugiados dispersos y reconocidos (Casillas, 1996: 5). Rojas y Ángeles proponen la siguiente clasificación para los centroamericanos que utilizan el Soconusco como lugar de destino: a) trabajadores agrícolas guatemaltecos, b) trabajadoras del servicio doméstico, c) mujeres que trabajan en el comercio sexual, d) comerciales de diverso tipo, e) empleados en servicios y f) menores trabajadores (Rojas y Ángeles, 2003: 15-17).

Los primeros guatemaltecos presentes en el Soconusco eran hombres y mujeres provenientes sobre todo de los departamentos de Quetzaltenango y San Marcos, y de regiones próximas, que habían tejido fuertes lazos sociales, culturales y de parentesco con sus pares chiapanecos (INM et al., 2006: 18). Esa urdimbre fue tejida en el marco de una relación centenaria basada en la libre circularidad de las poblaciones, misma que pretendió ser modificada a finales del siglo XIX en aras de los proyectos nacionalistas gestados sobre todo desde el lado mexicano, una de cuyas manifestaciones más visibles fue el establecimiento de la vida en frontera ${ }^{4}$ ajena a dichas poblaciones. En efecto, en 1882 quedaban establecidos los límites entre las dos naciones, en virtud de los acuerdos llegados en el Tratado sobre Límites entre México y Guatemala, en cuyo artículo primero se lee que este último país "renuncia para siempre los derechos que juzga tener al territorio del Estado de Chiapas y su Distrito de Soconusco y, en consecuencia, considera dicho territorio como parte integrante de los Estados Unidos Mexicanos". 5

No obstante lo anterior, el intercambio entre los dos pueblos no mermó, sino que se intensificó debido a los acontecimientos que se dieron casi simultáneamente: los guatemaltecos iban a trabajar más al Soconusco, con la irrupción de las fincas cafetaleras en muchos de los municipios soconusquenses y la explotación del cacao. Las condiciones se daban en la región chiapaneca 
para que, a inicios del siglo $\mathrm{XX}$, se incrementara sustancialmente la demanda de mano de obra agrícola, lo cual se sumó a la turbulencia social y política del lado guatemalteco que derivó en la expropiación de tierras comunales a los indígenas para ser vendidas a los extranjeros, sobre todo europeos, a fin de que estos últimos las explotaran en cultivos como el café. Comenzó la emigración masiva de "trabajadores agrícolas guatemaltecos" hacia la próspera región chiapaneca, que se prolongó durante todo el siglo XX y que llega a ser imprescindible hasta nuestros días.

En 1978 había en Chiapas unos 32,000 jornaleros originarios de Guatemala; en 1982, en pleno genocidio que ocurría en muchas aldeas y poblados de este país centroamericano, la cifra se incrementó a 75,000. Pronto, la mano de obra guatemalteca desplazó a la chiapaneca que provenía de Los Altos y otras regiones (De Vos, 2005: 18; Rojas y Ángeles, 2003: 15). En la actualidad, la presencia de la mano de obra guatemalteca en el Soconusco y otras regiones chiapanecas como la Frailesca y Fronteriza es innegable. El INM, por ejemplo, expidió 30,080 Formas Migratorias de Trabajador Fronterizo, FMTF, en todo el año 2009, de las cuales se emitieron 25,652 a guatemaltecos que ingresaron por los puntos de internación del Soconusco: Ciudad Hidalgo, 841; Talismán, 25,524; Unión Juárez, 87, para trabajar en labores fundamentalmente agrícolas. ${ }^{6}$ Esta cifra, alta de por sí, denota una disminución con respecto a la emisión de las anteriores formas migratorias, como se aprecia en el Cuadro 1.

Esto podría tener múltiples explicaciones, como por ejemplo la disminución en la demanda de mano de obra que resultaría de la crisis experimentada por algunos cultivos desde la década pasada —el café, por ejemplo-, consecuencia, a su vez, de los bajos precios en el mercado internacional. Los datos actuales, como los anteriores, se refieren únicamente a los cruces legales y documentados, dejando por fuera todo un universo de ingresos irregulares o indocumentados; otra de las limitaciones de este registro es que los datos no se desglosan por sector laboral de ocupación, por lo que no podemos distinguir la cantidad de trabajadores documentados que se ocupan en labores no agrícolas, como el servicio doméstico, el comercio y la construcción, por decir algunos.

La llegada de familias guatemaltecas a las fincas del Soconusco - patrón que se repite en la actualidadpropició el surgimiento de otro grupo migratorio, distinto en cuanto a trayectoria laboral y destino, igual en lo tocante al origen: las mujeres, adolescentes y niñas, que en principio acompañaban a sus padres $y$ madres en las labores agrícolas y que paulatinamente se fueron dedicando a tareas domésticas, conformando el grupo que hoy se conoce como "trabajadoras del servicio doméstico", en su mayoría jóvenes indígenas guatemaltecas originarias del departamento de San Marcos (Rojas y Ángeles, 2003: 16). El destino privilegiado por este grupo es todavía Tapachula, la cabecera regional.

Chiapas conoció otro flujo masivo de migrantes guatemaltecos: 50,000 o 60,000 personas llegaron a la entidad en calidad de refugiados, huyendo de la represión militar generalizada en los departamentos de Huehuetenango, Petén, El Quiché y Alta Verapaz (INM et al., 2006: 21). Este flujo no se estableció únicamente en el Soconusco, ni siquiera sólo en Chiapas, pero es imprescindible referirse a él, pues vino a contribuir al establecimiento de la vida transfronteriza que caracteriza a la región desde antaño. Aproximadamente 42,000 refugiados regresaron a sus comunidades de origen en Guatemala desde mediados de los ochenta; otros se quedaron al obtener la nacionalidad mexicana. En efecto, en 1996, luego de la firma de paz en Guatemala, se dio el retorno desde Campeche y Quintana Roo, y en 1998 desde Chiapas (Kauffer, 2005a: 8). Kauffer distingue dos maneras de esta repatriación o retorno: la primera, individual, "promovida en primer lugar desde 1984 por el gobierno guatemalteco y realizada en condiciones dudosas con respecto a los derechos humanos", que se 
prolongó hasta 1999; la segunda, colectiva y organizada, que se dio entre 1993 y 1999 (Kauffer, 2005b: 192).

En todo caso, los lazos quedaron tendidos entre las gentes y lugares de destino y origen de la migración forzada (Kauffer, 2002: 215). La autora califica el refugio guatemalteco en el sureste mexicano como un "movimiento migratorio forzoso". Lo describe así: "el refugio es una migración forzosa, no procede de una decisión voluntaria, pensada con anticipación, sino que constituye en muchos casos la única alternativa para salvar su vida" (Kauffer, 2002: 216). Añade otro autor que "el desplazamiento forzoso se convirtió literalmente en una estrategia de sobrevivencia" (Castillo, 2003).

La llegada de centroamericanos de otras nacionalidades es más reciente, en términos comparativos. Conocemos muy poco de esos otros flujos. Los primeros salvadoreños y hondureños habrían llegado a trabajar a las plantaciones tradicionales, café y cacao, y a los cultivos surgidos de la diversificación agrícola en Chiapas, como el algodón, el plátano, la caña de azúcar, la papaya y el mango; cultivos que, exceptuando el primero, son todavía importantísimos en la región. Dicho flujo migratorio fue favorecido desde la segunda mitad del siglo XX, con la construcción de diversos tramos de la carretera del litoral — conocida en Guatemala y El Salvador como CA-2, segunda en importancia en dichos países-, que conecta directamente con la ciudad de Tapachula, cambia de nombre en Chiapas, Carretera 200, y se prolonga por el corredor del Soconusco y la Costa, pasando por o conectando con otras ciudades como Huehuetán, Huixtla, Escuintla, Mapastepec, Pijijiapan, Tonalá y Arriaga, que a su vez conecta con el istmo de Tehuantepec en el estado de Oaxaca. Concomitante al crecimiento urbano de la ciudad de Tapachula y la conectividad con Centroamérica creció la demanda de trabajadores ocupados en el sector terciario - sobre todo en el comercio y los servicios - y la construcción, diversificando así la trayectoria laboral y la composición nacional de los centroamericanos en el Soconusco.
El flujo significativo más reciente lo constituyen los migrantes en tránsito, que se internan irregularmente a México con la intención de llegar a Estados Unidos. Como ya se apuntó arriba, los centroamericanos representan el flujo más importante de extranjeros en esas condiciones, a juzgar por las estadísticas de deportaciones ejecutadas por INM durante los últimos años (ver Cuadro 2). Nótese cómo en 1999 los centroamericanos aportaron casi 97\% de todos los aseguramientos realizados por la autoridad migratoria; en 2008 esa participación se mantuvo prácticamente intacta: $96.3 \%$.

Los migrantes en tránsito utilizan los accesos del Soconusco como puerta y como puente, aunque han diversificado las rutas debido a los riesgos que presenta la región. Siguen utilizando las vías tradicionales, las carreteras, los caminos rurales y de extravío y, durante mucho tiempo, las vías del tren, hasta que en 2005 quedaron inservibles luego del desastre provocado por el huracán Stan. Como ya se apuntó arriba, los guatemaltecos, hondureños, salvadoreños y nicaragüenses alimentan dicho flujo. El resto de centroamericanos - costarricenses, beliceños y panameños - tienen una presencia nimia en las estadísticas de aseguramientos, por lo que no son considerados en este artículo, aunque también ellos transitan por el territorio mexicano de manera irregular, al igual que los nacionales de Ecuador, Colombia, Brasil, Perú, Cuba y una cantidad desconocida de migrantes extra continentales.

\section{Presencia en la ausencia ${ }^{8}$}

La primera paradoja conduce a la segunda: los centroamericanos son, naturalmente, los extranjeros que mayor presencia tienen en esta región chiapaneca; no obstante, y sólo en contadas excepciones, no aparecen en los registros oficiales, más allá de los eventos de aseguramiento del INM, en su calidad de migrantes que transitaban en situación irregular. 
Sin embargo su presencia no se agota allí. En lo que sigue - $y$ en ausencia de registros cuantitativos-, se reseña a partir de material etnográfico algunos casos de migrantes centroamericanos que se encuentran en al menos tres posibilidades abiertas durante sus trayectorias migratorias. La primera posibilidad es que queden en alguna localidad del Soconusco, modificando sus trayectorias migratorias al abandonar un proyecto inicial de llegar a Estados Unidos - los que se quedanHabría que apuntar, empero, que cada vez se vuelve más común encontrar casos de centroamericanos - no solo guatemaltecos - que sí consideraron desde la salida de sus países quedarse a vivir en la región. En segundo lugar, se consideran casos de migrantes en tránsito, que utilizan el Soconusco como puerta y como puente, en su ruta hacia Estados Unidos - los que se van-. Los dos constituyen flujos en dirección sur-norte, con muy variadas motivaciones para emigrar - aunque la situación de violencia e inseguridad en sus países es cada vez más determinante- $-y$ diferentes experiencias en el camino. Lo que tienen en común es que se trata, en su gran mayoría, de migrantes que se internan a México en situación irregular.

Una tercera posibilidad es que los centroamericanos sean asegurados por las autoridades mexicanas mientras transitaban hacia los Estados Unidos y, como consecuencia de esto, se encuentren en proceso de devolución a sus países - los que regresan forzadosun flujo que va en dirección norte-sur, escasamente estudiado por sus peculiaridades: de difícil acceso para los investigadores - considerando las restricciones impuestas por las autoridades migratorias - y en condiciones desfavorables cuando se les encuentra; ${ }^{9}$ además, se trata de un flujo en dirección "contraria", que por el mismo hecho pareciera ser irrelevante. Dado que no portan los documentos que faculten su estadía legal, los centroamericanos asegurados han sido interceptados por las autoridades mexicanas ${ }^{10}$-federales, estatales, municipales - a lo largo y ancho de todo el territorio nacional, conducidos a cualquiera de las 27 estancias y estaciones migratorias del sureste o las 25 situadas en el resto de la República (Casillas, 2007: 23), y llevados finalmente por vía terrestre a la Estación Migratoria Siglo XXI, en la ciudad de Tapachula, desde donde se ejecuta su deportación, también por vía terrestre. Con todo, las posibilidades acá mostradas no son para nada herméticas: un migrante en tránsito puede prolongar su estadía en el Soconusco mientras trabaja, ahorra y puede proseguir su viaje hacia la frontera con Estados Unidos; o bien los deportados pueden internarse de nuevo en territorio mexicano incluso el mismo día, volviendo a ser formalmente migrantes en tránsito.

\section{Los que se quedan}

No se sabe a ciencia cierta cuántos se quedan en el Soconusco, abandonando su intención inicial de sólo transitar por esta región; pero su presencia es significativa, según se desprende de testimonios de funcionarios consulares, miembros de organizaciones civiles que les atienden y de observaciones realizadas en el campo, además de los pocos datos estadísticos

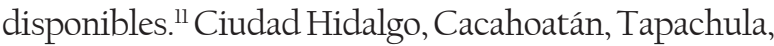
Puerto Madero, Mazatán, Huehuetán o Huixtla, cualquier ciudad o localidad de la región, por diversas circunstancias y decisiones personales tomadas en el camino, puede dejar de ser un lugar de tránsito y convertirse, de súbito o paulatinamente, en un sitio de destino de los migrantes centroamericanos. Quedarse es un imperativo cuando los recursos — que la mayoría de las veces son limitados- escasean en el camino. Quedarse tampoco es una opción descartable cuando se establecen lazos y se tejen redes lo suficientemente fuertes como para modificar drásticamente una trayectoria que, en principio, los llevaría a Estados Unidos o algún estado mexicano situado en el centro o el norte de la República.

Otros se quedan, esta vez súbita y trágicamente, tras sufrir un accidente o cualquier circunstancia que les imposibilite continuar su viaje. Se trata de los que se 
ven expuestos a situaciones de riesgo — caer del tren, ser herido gravemente por un asaltante, etcétera- y no salen bien librados de ellas. Estos últimos permanecen atrapados en una especie de limbo migratorio: no pueden seguir adelante por sus limitaciones físicas o emocionales y no quieren regresar a sus países, donde les esperan manos y bocas ansiosas de la remesa mensual. ${ }^{12}$ No todas las historias, empero, son de fracaso.

Álvaro es guatemalteco y Patricia salvadoreña. ${ }^{13}$ Viven juntos en un ejido de Mazatán desde 1999. Ahora tienen cuatro hijos nacidos en territorio mexicano. Ambos incluyeron alguna vez en sus planes emigrar a Estados Unidos, pero decidieron quedarse en el Soconusco. Álvaro sabe del cultivo de papaya, banano, mango, ajonjolí y maíz. Actualmente cultiva estos dos últimos en un pequeño terreno que le han prestado en el ejido Adolfo Ruiz Cortines. La familia vive del campo. De mayo a octubre, Álvaro siembra la primera cosecha de maíz; en agosto siembra la segunda. Produce tres toneladas en cada cosecha y por cada tonelada le pagan 2,500 pesos, quedándole la mitad al quitarle todos los gastos. Es decir, el valor de la producción anual de maíz de Álvaro es de unos 15,000 pesos, de los cuales le quedan unos 7,500 libres. Desde el 2007, se animó a sembrar ajonjolí, cuya cosecha es más corta - tres meses- y se paga mejor. La familia guarda su maíz para todo el año y los demás alimentos los compra en el centro de Mazatán, a pocos kilómetros de su vivienda.

En un día normal, Patricia prepara el desayuno y alista a Álvaro y Elena, los dos chicos que estudian en la escuela primaria de la localidad, que se encuentra aproximadamente a 300 metros de la vivienda. La mujer se queda cuidando a sus otros dos hijos, mientras Álvaro, el padre, se marcha al terreno a cuidar la siembra o a la oficina del comisario ejidal, quien le encarga algunos mandados, por los que percibe eventualmente un ingreso extra. El comisario es un apoyo de la familia, pues en caso de necesidad han acudido a él, como cuando el guatemalteco enfermó casi por un mes y no pudo trabajar. Aquel le llevó medicamentos y dinero, a cambio de los favores. Normalmente la familia no sale de Mazatán. En raras ocasiones van a Tapachula, a realizar algún trámite. Patricia, por ejemplo, sólo conoce desde Ciudad Hidalgo hasta Mazatán, un radio de unos 70 kilómetros dentro del territorio chiapaneco. Más allá no ha ido nunca y no le parece necesario hacerlo. Lo mismo sucedía en El Salvador, en donde no conocía más que unas pocas localidades del occidente del país, de donde es originaria. El grupo familiar completo los seis miembros - nunca ha salido de México, pero planean visitar Retalhuleu, en Guatemala, y Jujutla, en El Salvador, lugares de donde son originarios el padre y la madre, respectivamente, "para que los niños conozcan a sus abuelos". Álvaro y Patricia decidieron regularizar su situación migratoria para vivir en Mazatán, quedarse allí y darles educación a sus cuatro hijos. Opina la salvadoreña:

Yo no quiero repetir la misma historia. Mis papás me dieron educación sólo hasta el tercer grado porque éramos bien pobrecitos. Sólo un hermano llegó como a octavo o noveno grado [segundo o tercero de secundaria]. Dos hermanos míos estudian todavía en El Salvador. Mis hijos están mejor acá. ${ }^{14}$

Los que se quedan modificando sus trayectorias también se asientan en colonias de la periferia de las ciudades o en asentamientos irregulares, rentando cuartos y habitaciones que muchas veces no reúnen las condiciones habitacionales mínimas. En la Colonia Cahoacán de Tapachula, por ejemplo, justo en los alrededores del Albergue Belén, se ha formado durante los últimos años una pequeña infraestructura de servicios para satisfacer ciertas demandas — tarjetas telefónicas; artículos de consumo como refrescos, agua embotellada, panecillos y cigarrillos; renta de pequeñas habitaciones; alimentos preparados, etc.- de los migrantes en tránsito que se hospedan en la casa del migrante y también de los llamados localmente "rezagados", es decir, aquellos que por diversas causas 
no pudieron continuar su viaje y deambulan por el albergue en busca de algún trabajo, algún contacto o, simplemente, persiguiendo conquistar a algún migrante a fin de que este le apoye para continuar su viaje.

Julio, salvadoreño de 43 años, llegó al Albergue Belén a finales de 2007. Solicitó la calidad de refugiado ante la Comisión Mexicana de Ayuda a Refugiados, COMAR, debido a que en El Salvador había sido amenazado de muerte por un grupo de policías corruptos. Estos habían fallado ya en un intento de asesinarle. El trámite de Julio fue resuelto desfavorablemente y, por la ausencia de recursos y la imposibilidad de regresarse a su país, quedó rezagado, como muchos, en Tapachula. A inicios de 2008, rentaba junto con un nicaragüense un cuarto ubicado a unos 200 metros del albergue, sobre la calle que conecta el fraccionamiento Los Laureles con la colonia San Antonio Cahoacán. La pequeña vivienda está formada por un cuarto grande, de unos 20 metros cuadrados, seguido de un espacio de servicio, con lavadero y una pila. En la parte de atrás hay una pequeña cocina improvisada de leña, en la que los dos preparan el café por las mañanas. El menú diario, naturalmente, no es nada balanceado. Cuando hay cierta liquidez, Julio toma su almuerzo y cena en un comedor que se encuentra en las cercanías; la dueña del mismo le permite fiar mientras aquel recibe el precario salario que devenga como ayudante de la construcción. Las únicas pertenencias de Julio y su compañero son dos colchones, levantados por ladrillos y a poca altura del piso, así como un escaso ajuar. No hay más muebles que una silla vieja. Las condiciones de vida y el acceso a algunos servicios son igualmente limitados entre los otros migrantes que rentan en la zona.

Los centroamericanos, pues, se asientan en las principales localidades del Soconusco; en Tapachula también se concentran en las colonias más populosas. Otros, pero muy pocos, consiguen prolongar su estancia en el Albergue Belén, negociando con sus responsables, donde en principio se quedarían únicamente tres días. Se emplean en la construcción como albañiles, carpinteros y ayudantes; en talleres de mecánica automotriz; en el comercio informal o en restaurantes y cantinas. El objetivo es reunir el dinero suficiente para proseguir su viaje. Otra buena parte se queda en las fincas o en pequeñas parcelas, ocupándose en labores agrícolas, como lo hizo Álvaro; de hecho, el guatemalteco conoció a Patricia en una bananera cercana de Ciudad Hidalgo, donde su futura mujer llegó a trabajar junto con otras 50 mujeres centroamericanas, entre guatemaltecas, salvadoreñas y hondureñas. Muchos migrantes diversifican sus ocupaciones agrícolas, siguiendo las temporadas del café, el mango, la papaya y la caña de azúcar.

Los que se quedan y han permanecido en México sin sus documentos en regla tienen la opción de acogerse al programa de regularización migratoria que ejecuta INM desde hace ya varios años, en el marco del cual se les reconoce como "inmigrantes" y se les extiende un documento FM2. ${ }^{15}$ Entre enero y octubre de 2009, por ejemplo, esa dependencia resolvió favorablemente las solicitudes de 2,713 extranjeros que se ampararon al programa, de los cuales 2,024, es decir $74.6 \%$, correspondieron a centroamericanos: 2 beliceños, 8 costarricenses, 286 salvadoreños, 891 guatemaltecos, 696 hondureños, 133 nicaragüenses y 8 panameños. Es significativo que 1,457 solicitudes, $53.7 \%$ del total, fueron resueltas para extranjeros que radicarían en Chiapas. Lamentablemente, como en el caso anterior, el registro arroja datos que, pese a su valía, solo cuantifican una mínima parte de la población centroamericana residente en México.

\section{Los que se van}

Tampoco se sabe con certeza cuántos se van y alcanzan a llegar hasta la frontera norte mexicana o al menos pasar de Chiapas y Tabasco, donde ocurre la mitad de todos los aseguramientos que realizada INM. Pero sí se sabe que muchos siguen pasando por el Soconusco y la Costa, pese a que una de las rutas que ha cobrado 
relevancia desde 2005 es la del Golfo, que comienza para los centroamericanos en la localidad tabasqueña de Tenosique. Siguen atravesando Tapachula porque les resulta familiar desde su país de origen y, sobre todo, más económico, aunque no menos riesgoso. Les resulta familiar en los relatos divulgados sobre todo por los medios de comunicación. Llegan allí y pueden mimetizarse en una sociedad que ya se acostumbró a ellos, aunque una parte de ella no los tolera y los discrimina. No hay otra localidad parecida a Tapachula más adelante. Conforme se internan en el territorio mexicano difícilmente pueden confundirse y pasar desapercibidos. Están expuestos a las autoridades y a personas particulares, que se lucran de ellos. Saben de los riesgos, pero eso no los detiene. Siguen llegando y caminando, sin detenerse. Demoran siete días en promedio, si caminan desde Tapachula hasta el otro extremo de Chiapas, Arriaga, donde encuentran el siguiente albergue y pueden descansar otros tres días, antes de abordar el tren de carga que los conducirá por Oaxaca y Veracruz rumbo al centro del país. En el trayecto son presa de asaltantes, pandilleros y autoridades. Los que cuentan con un mínimo de recursos viajan en transporte público, librándose de los asaltantes, pero son presa fácil de los agentes de INM y de la Policía Federal, que se sitúan en al menos tres puntos de revisión migratoria y cuatro policiales por el corredor del Soconusco y la Costa - Huehuetán, Huixtla, Pijijiapan-, además de los retenes militares y las impredecibles "volantas". ${ }^{16}$

La convivencia entre mexicanos y centroamericanos en estos espacios de tránsito y residencia temporal/ definitivaestámediadapormecanismosdediferenciación social, entre los cuales los más determinantes parecen ser la nacionalidad, el género, la filiación étnica y la ocupación laboral, que inciden a su vez en el grado de vulnerabilidad que los últimos presenten. Además, mucho de lo que ocurre en la interacción cotidiana entre unos y otros está enlazado según los centroamericanos sean migrantes en tránsito o migrantes residentes en alguna de las localidades de la región. Así, en términos generales, las poblaciones locales como las mismas instituciones del estado suelen ser menos tolerantes con los migrantes en tránsito, a quienes — salvo las excepciones que tienen que ver con iniciativas muy concretas, como los mecanismos de solidaridad, surgidas desde organizaciones civiles y religiosas - se busca interceptar, sacar provecho o simplemente evitar, según sea la adscripción social de la persona mexicana.

Es predecible que, por ejemplo, un agente federal de migración busque asegurar a un grupo de migrantes centroamericanos que logró avistar en un camino de extravío en Huixtla o que un triciclero ${ }^{17}$ en Ciudad Hidalgo busque cobrar unos pesos de más a una pareja de nicaragüenses que por su semblante denote no tener idea alguna del lugar por donde transita. Aunque pueda haber muchas interpretaciones y posiciones al respecto, lo cierto es que mucha de la gente en el Soconusco policías, agentes de migración, contratistas, prestadores de servicios, personas comunes y corrientes- sabe distinguir a un migrante en tránsito que descansa entre un grupo de gente que se pasea en el parque Miguel Hidalgo de Tapachula en día domingo. Ello tiene que ver con sutiles mecanismos de percepción y autopercepción.

Por el contrario, suele haber mucha más receptividad hacia los flujos de centroamericanos que llegan a la región con la intención de radicar allí o que paulatinamente fueron abandonando su proyecto inicial de únicamente transitar por ella. Un estudio reciente que indagó sobre la percepción que los tapachultecos tienen hacia la migración y los migrantes reveló cómo aquellos estarían más dispuestos a aceptar a que las mujeres centroamericanas se queden a vivir en la región y que lo primero que pensaría la gente de a pie al ver a un migrante en solitario es que este le va a pedir ayuda, y al ver a un grupo de migrantes es que estos le van a asaltar (Insyde, 2008: 18). Es notable como, por ejemplo, en los hogares tapachultecos de clase media se prefiera contratar como empleadas domésticas a 
mujeres indígenas guatemaltecas — que se presume sólo tienen interés en trabajar en Tapachula- que a mujeres hondureñas o salvadoreñas - que se presume únicamente están juntado dinero para seguir su viaje hacia Estados Unidos y no escapan del mote de las "quitamaridos".

Los que se van, es decir, los migrantes en tránsito, constituyen uno de los flujos menos estudiados, por su fugacidad y anonimato, aunque se ha visto un notable incremento de trabajos realizados durante los últimos cinco años. Los que se van procuran pasar desapercibidos, porque el anonimato les brinda seguridad. Se les encuentra en el cruce fronterizo abordando las "cámaras", ${ }^{18}$ pasando el Río Suchiate o abordando unidades de transporte público del lado mexicano. Se les encuentra también en los albergues y casas de migrantes, donde es más fácil acercarse a ellos, pues no se les pone en riesgo: en la casa del migrante de Tecún Umán, al lado guatemalteco de la frontera; en los albergues Belén y El Buen Pastor, de Tapachula; en el "descanso" que ha habilitado una iglesia católica en Huixtla; y en el Hogar la Divina Misericordia, de Arriaga. Allí descansan y comen durante tres días o el tiempo necesario, además de poder curarse de sus lesiones, que son más graves cuando llegan a Arriaga. También se les halla descansando debajo de los puentes, caminando por la maltrecha vía del tren o por los llamados caminos de extravío, marcados entre la maleza por los mismos migrantes que rodean los retenes para no ser detectados por las autoridades.

Sin embargo, ante los riesgos y en determinadas situaciones, los que se van han elaborado una serie de estrategias, algunas más finas que otras. No solo modifican constantemente las rutas, una de las estrategias más visibles y predecibles. Saben también que parientes, amistades y paisanos que les precedieron y se quedaron en el camino son aliados imprescindibles, por lo que procuran apoyarse en ellos durante su travesía. Se apoyan, por ejemplo, en los que se han quedado en alguna localidad del Soconusco para conseguir alojamiento o un trabajo, si se prolonga la estancia. Si tienen familiares en Estados Unidos dispuestos a apoyarles con el envío de dinero, únicamente solicitan cantidades menores y desde ciudades en que hallen la seguridad de al menos recibirlas.

Cuando no hay redes de apoyo preexistentes, se tejen en el camino. Los vínculos pueden ser efímeros y/o, paulatinamente, duraderos. Por ejemplo, muchos de los que se van se encuentran en la casa del migrante de Tecún Umán, del lado guatemalteco, y unen esfuerzos para llegar a Tapachula o seguir más adelante, si la voluntad no flaquea. Los que conocen las rutas y no tienen dinero se unen con los que tienen dinero y no conocen las rutas; se dan casos de "sexo transaccional" o "de supervivencia", en los que las mujeres acceden a tener sexo con otros migrantes a cambio de una precaria y relativa seguridad; los que conocen detalles del viaje intercambian la información que guardan, esperando siempre sacar provecho de ello. Se trata pues de una constante negociación e intercambio, en donde la norma es la escasez de recursos económicos y el ingente deseo de llegar a Estados Unidos lo más pronto posible.

En el Albergue Belén abundan ejemplos de lo anterior. Daniel, Roberto y José, tres salvadoreños que partieron de su país rumbo a Estados Unidos, tocan las puertas del albergue en un día de septiembre de 2007, justo antes de que se sirva la cena. Daniel y Roberto eran vecinos en la colonia Zacamil, una zona populosa de la capital salvadoreña. El mayor de los tres, Daniel, ha llegado con camisa formal de manga larga, "para verme formal y despistar a los de migración", confiesa. Dentro de su camisa lleva otra más sencilla. En su mochila a penas guarda otra mudada de ropa y unas pocas cosas. Roberto, el más chico, tiene una presencia diametralmente opuesta: viste pantalones anchos y una camiseta desmangada que deja ver un par de tatuajes en ambos brazos. No son alusivos a las pandillas, sino más bien de un típico muchacho marginal de los suburbios de San Salvador. Roberto ni siquiera lleva una mochila. Ambos son jóvenes de extracción urbana pero 
provienen de situaciones precarias. José, originario del departamento de Santa Ana, tiene un aspecto y acento diferentes: es originario de la zona rural del occidental departamento. Los tres se han unido para atravesar el territorio mexicano sin papeles.

Roberto va en su sexto intento. Ha sido deportado dos veces desde la frontera entre México y Estados Unidos, y el resto no ha pasado del sureste mexicano, pues ha sido detenido antes de atravesarlo. No ha pisado suelo estadounidense nunca. Tiene conocimiento de algunas estrategias vitales en el trayecto, como moverse en transporte público y bajarse del mismo antes de llegar a una caseta migratoria, rodear esta última y tomar otro medio de transporte. Asegura conocer toda la ruta del Golfo hasta la frontera con Estados Unidos. En cierto modo, es el guía del grupo. Daniel y Roberto partieron juntos de San Salvador. "Este salió con cinco dólares y yo con diez", relata Daniel, con la esperanza de recibir los 50 dólares que le pidió a su madre en cuanto llegó a Tapachula. Sabe que no debe llevar mucho dinero, en caso de ser asaltado o extorsionado por alguna autoridad o persona particular. "Con ese pisto ${ }^{19}$ queremos llegar los tres hasta Arriaga”, añade. La pareja no tomó autobús directo de San Salvador a Guatemala, sino que fue transbordando, para abaratar los costos. Así, los 15 dólares que habían juntado desde su partida ajustaron únicamente hasta la capital guatemalteca. Pidieron ayuda en distintos lugares y recibieron apoyo monetario y alimentos. Daniel añade airoso:

Logramos juntar como 150 quetzales. La gente nos daba de comer. A mi me daba pena al principio, pero después se me pasó. Bien buena onda la gente porque se portó bien, pero fijáte [sic] que les dijimos que veníamos desde Nicaragua, para que vieran que éramos de más lejos. ${ }^{20}$

Con lo recaudado llegaron hasta el Albergue de Tecún Umán, pero una vez más sin dinero. Allí aparece en escena José, el santaneco, quien tenía cierta liquidez, pero no conocía más adelante y dudaba en seguir. "No conocía nada a partir de allí. Le ayudamos porque el vato $^{21}$ andaba perdido", detalla Daniel. Convencieron a José para que se uniera al viaje y desde entonces formaron una caja común. Al día siguiente, por la mañana y luego del preciado desayuno, los tres partieron hacia Tapachula. La primera prueba a vencer era pasar al otro lado del Río Suchiate sin ser detenidos. Se aventuraron por el puente internacional, para no pagar las cámaras, y lograron pasar sin problemas, lo cual evidencia la porosidad de este paso fronterizo. Con el dinero que aportó Juan y que prometió devolver Daniel en cuanto le enviaran desde Estados Unidos, abordaron una unidad de transporte público desde Ciudad Hidalgo hasta Puerto Madero y de allí a Tapachula. No tuvieron ningún contratiempo, aunque llegando al albergue, los tres a penas juntaban unos cuantos pesos. En este caso, las expectativas mutuas y la escasez fueron suficientes elementos para formalizar un lazo entre tres personas, sobre todo con el tercer joven, a quien no conocían.

Los que se van, en definitiva, parecen ser los principales portavoces de los que se quedan: son ellos los que aparecen en los registros oficiales y en las notas periodísticas. En estas últimas, la nota predominante tiene que ver con una triste y penosa realidad para México como país de tránsito, pues sobre los centroamericanos recaen prácticas violentas que han llegado a institucionalizarse en distintos niveles del tejido social. Si se ingresa la frase "migrantes centroamericanos" en cualquier buscador de Internet de México se sorprendería el espectador sobre la cantidad de noticias relacionadas con abusos y agresiones cometidas en desmedro de la integridad física y moral de aquellos, muchos de los cuales han acabado con sus vidas. Esta es otra paradoja que merece un renglón aparte y que por cuestiones de espacio no se incluye aquí. Buena parte de los que se van no alcanzan a llegar a su destino y ven frustradas sus aspiraciones dentro de las paredes de una estación migratoria. Esta es una tercera posibilidad. 


\section{Los que regresan forzados 22}

Pocos repatriados regresan voluntariamente (Caso et al., 2006: 10). Se dispone de cifras sobre los que regresan a sus tierras, deportados por INM y llevados hasta la frontera de su país (ver Cuadro 1). En diciembre de 2009, 45,763 guatemaltecos, hondureños, salvadoreños y nicaragüenses, fueron repatriados a sus países de origen por las autoridades mexicanas en el marco del "Memorándum de entendimiento entre los gobiernos de los Estados Unidos Mexicanos, de la República de El Salvador, de la República de Guatemala, de la República de Honduras y de la República de Nicaragua, para la repatriación digna, ordenada, ágil y segura de nacionales centroamericanos migrantes vía terrestre". 23 Todos los centroamericanos que fueron devueltos por la vía terrestre a sus países en el marco de aquel acuerdo habrían sido resguardados en la Estación Migratoria de Tapachula.

El proceso es como sigue. Luego de la verificación migratoria, los centroamericanos que no lograron acreditar supermanencia legal en México son asegurados y concentrados en cualquiera de las estaciones o estancias migratorias extendidas por todo el territorio nacional, para posteriormente ser conducidos por vía terrestre hacia la Estación Migratoria Siglo XXI de Tapachula, el más grande centro de resguardo de extranjeros sin papeles en toda América Latina. Este recinto es además sede de la delegación regional de INM en Chiapas - el despacho del funcionario migratorio de más alto rango en el estado y, junto con el de Tabasco, el que más debe firmar oficios de aseguramientos y repatriaciones de extranjeros en todo el país-. De este modo, la estación migratoria de Tapachula es la última parada en territorio mexicano durante el proceso de aseguramiento y deportación de los centroamericanos.

Con todo y que las autoridades migratorias ablanden el proceso mediante matices lingüísticos - aseguramiento, repatriación, falta administrativa y estación migratoria; en lugar de detención, deportación, delito y cárcel, respectivamente - la cotidianidad dentro de la Estación Migratoria Siglo XXI no difiere mucho de los recintos penales. Al inicio de la sección de hombres, los agentes federales reciben a los recién llegados, instruyéndoles en las normas de convivencia para luego pasar por el ritual de aseo. Se levanta un inventario de las pertenencias personales que serán devueltas cuando abandonen las instalaciones, algo que para fortuna de los centroamericanos ocurre muy rápido, a diferencia de los asegurados de otras nacionalidades y que INM llama "población restringida" -cubanos, sudamericanos, africanos y asiáticos, entre otros-. A medida los visitantes se internan a la sección masculina, el parangón presentado arriba se hace más evidente. Los dormitorios están dispuestos y construidos de modo que pueda ejercerse control visual sobre ellos. Al final de los comedores se encuentra el área de recreación, en donde puede apreciarse un mosaico étnico impresionante. Los más acomodados son los de nacionalidades restringidas, ya que llevan más tiempo allí y, generalmente, tienen más recursos. Los cubanos casi siempre son los más dispuestos a hablar, pues tienen más quejas que cualquier nacional de otro país.

Corre noviembre de 2007. Un hondureño y un salvadoreño, ambos solicitantes de refugio $\mathrm{y}$, por ende, con una estancia más prolongada, se ganan unos cuantos pesos lavándoles la ropa a los cubanos, que generalmente tienen más dinero, cigarrillos y privilegios. El cuadro lo completan los agentes de INM, que vigilan atentamente a los visitantes. El recinto contaba en ese año con tres grandes secciones para el resguardo de su población: la de hombres, la de menores varones no acompañados y la de familia, que incluye mujeres, niñas y menores acompañados. Las divisiones están bien marcadas. Por regla, nadie puede invadir el área que no le corresponde. Los dormitorios de los extranjeros están agrupados por nacionalidades, aunque algunas ocupaciones diarias — comidas, actividades deportivas y recreativas - son comunes, en principio. La permanencia de centroamericanos varía entre 
unas pocas horas y un par de días, según los trámites internos y del servicio consular, necesario para agilizar la deportación de menores de edad no acompañados. En raras ocasiones la permanencia de los centroamericanos excede una semana. Las excepciones tienen que ver con solicitudes de refugio, cuya resolución puede demorar semanas o meses.

Los solicitantes de refugio, un subgrupo de los migrantes centroamericanos en el Soconusco, merecen una atención especial que va más allá de lo dicho en estas líneas. De momento sólo digamos que su importancia es capital, en tanto que es creciente la presencia de gente originaria de Centroamérica que llega a México huyendo de situaciones en sus países de origen que comprometen su integridad física y moral. Al tradicional desplazamiento de grupos de centroamericanos que huían de la represión militar durante los conflictos bélicos vigentes en los años ochenta, lo ha venido a sustituir un nuevo éxodo: los que huyen de la violencia social y la inseguridad, una de cuyas manifestaciones más visibles son las maras o pandillas, amenaza de carácter regional que afecta también a México. Los centroamericanos que huyen de las pandillas en sus países encuentran en territorio mexicano la seguridad que echaban de menos, incluso en la región fronteriza, donde se tiene evidencia que operan las maras y pandillas presentes en Centroamérica, como la MS-13 y el barrio 18. ${ }^{24}$

Solicitar la calidad de refugiado en México no es algo fácil e implica una constante derrama económica, así como desgaste emocional para los centroamericanos. Tapachula, por su ubicación geográfica, concentra a dos instituciones que trabajan estrechamente sobre este asunto particular: la Comisión Mexicana de Ayuda a Refugiados, COMAR, dependencia de la Secretaría de Gobernación, y una oficina del Alto Comisionado de las Naciones Unidas para los Refugiados, ACNUR. Los solicitantes de refugio acuden a COMAR con el apoyo de alguna organización civil — como el Albergue Belén o el Centro de Derechos Humanos Fray Matías de
Córdova-, alguno de los consulados centroamericanos acreditados en la ciudad o de manera individual. Son entrevistados y exponen detalladamente los motivos que aducen para abandonar su país de origen. En lo fundamental, deben demostrar tener un temor fundado de que sus vidas peligran en sus países o, según sea el motivo de huida, fundamentar su caso. Casi nunca se reúnen las pruebas suficientes que, a criterio de un comité de elegibilidad, impliquen el reconocimiento de refugiado. Mientras tanto, los solicitantes ven alimentadas sus expectativas incluso por los mismos funcionarios de COMAR. A medida que pasa el tiempo, el entusiasmo disminuye y la desesperación entra en escena. Como se anotó líneas arriba, en lo absoluto se agota acá la discusión en torno a los solicitantes de refugio centroamericanos, sudamericanos y extra continentales, que han incrementado su presencia en Tapachula y otras localidades vecinas durante los últimos años.

Volvamos al proceso que se comenzó a reseñar arriba. Los centroamericanos salen casi todos los días de la Estación Migratoria. Los guatemaltecos son expulsados del país y conducidos hasta los puentes fronterizos de Talismán-El Carmen y Ciudad HidalgoTecún Umán, en la región fronteriza SoconuscoSan Marcos; el otro sitio de expulsión es el cruce Ciudad Cuauhtémoc-La Mesilla, en la región SelvaHuehuetenango, más al norte. Son los que tienen más posibilidades de regresarse a México el mismo día, si es que no han desistido de seguir intentándolo. Los hondureños son expulsados del país por Talismán y llevados hasta la frontera entre Honduras y Guatemala por la aduana de Corinto, ubicada al norte. Hasta el año 2006 eran llevados al paso fronterizo de Agua Caliente, entre los fronterizos departamentos de Ocotepeque y Chiquimula, respectivamente.

Los hondureños deportados recorren en autobús más de 700 kilómetros, entre Tapachula y la frontera de Corinto, por lo que difícilmente pueden volverse a México el mismo día. Tienen que esperar al día 
siguiente, si es que aún hay recursos para el nuevo viaje. Deben llegar de nuevo al departamento de Chiquimula o la ciudad de Guatemala y, desde allí, enfilarse hacia el norte de Petén o San Marcos, en el sur, dependiendo del lugar por donde pretendan internarse irregularmente a México en un nuevo intento. Cuando eran llevados a la aduana de Agua Caliente tenían la opción de quedarse un par de días en la casa del migrante de la parroquia San José de Ocotepeque, a 24 kilómetros de la frontera, en territorio hondureño, único albergue en la región. Los salvadoreños son conducidos hasta el puente fronterizo Pedro de Alvarado-La Hachadura, cerca del litoral pacífico, donde no hay ningún albergue, ni muchas posibilidades de quedarse. La distancia es de unos 325 kilómetros, considerablemente menor que en el caso de los hondureños. Muchos regresan a sus lugares de origen a retomar fuerzas o a juntar un poco más de dinero, en un país que se recorre en su parte más larga en apenas unas seis horas. Los nicaragüenses son conducidos hasta el puente fronterizo de Guasaule.

Veamos, finalmente, dos casos documentados en la Estación Migratoria. Ana es salvadoreña y Carmen hondureña. Las dos estaban resguardadas en noviembre de 2007 y esperaban ser repatriadas a sus países. Cada una describe trayectorias diametralmente opuestas en cuanto a motivos para emigrar, experiencias en el camino y expectativas. Ana y Carmen toman su almuerzo en la misma mesa, pero sus experiencias migratorias difieren drásticamente. Sus semblantes hablan de lo lúdico y de lo trágico de la migración indocumentada femenina. ${ }^{25}$ En el comedor hay otras mujeres y sus hijos, todos centroamericanos. Las cubanas que estaban presentes comen después y procuran no mezclarse con las otras. Carmen vivía en Miami y había ido a Honduras a rescatar a su hija de las pandillas de Tegucigalpa:

¿Y cómo nos van a deportar ahora? ¿Cómo va a creer que voy a querer ir de regreso para Honduras, si vengo huyendo de allá? Yo le quiero pedir ayuda al cónsul pero no ha venido. Dicen que va a venir, para que me ayude. ${ }^{26}$

Ana, por el contrario, espera su pronta deportación y comunicarse de nuevo con el coyote, que la espera por otros cuatro intentos para llevarla hasta su destino por el mismo costo — seis mil dólares-. Se siente muy tranquila en la Estación Migratoria, pues come bien y sin ningún costo y esfuerzo:
¿Yo de qué me quejo? Acá estoy bien; tranquila. Tengo tres tiempos de comida, sin pagar nada. Lo tratan bien a uno. Son bien amables. No me quejo de nada. Si lo único ahora es que me regresen rápido a la frontera para darle otra vez. El coyote me va a llevar otra vez porque así fue el acuerdo. Uno tiene derecho a cinco intentos con él por el mismo precio. ${ }^{27}$

La Estación Migratoria Siglo XXI quizá no sea el espacio social idóneo para ilustrar la presencia centroamericana en el Soconusco: no es formalmente ni el sitio de destino ni el de tránsito. Nadie quiere estar allí, y si se está en la mayoría de los casos no lo es por voluntad propia. Pero esto no le resta importancia en términos analíticos. Buena parte de los que regresan forzados a sus tierras han visto frustrados sus sueños dentro de las paredes de ese recinto. La estación migratoria constituye un espacio liminar, donde no se está ni en el allá imaginario - Estados Unidos- ni en el acá originario -Centroamérica-. Pero constituye un espacio en el que cotidianamente los centroamericanos retoman más fuerzas o desisten de una vez por todas en su periplo migratorio.

\section{Consideraciones finales}

Las escasas fuentes cuantitativas apenas nos permiten mostrar la "centroamericanización" del Soconusco a partir de su población residente. En ausencia de una 
base de datos que cuantifique la población de origen extranjero radicada en la entidad chiapaneca y en la región soconusquense hemos de echar mano de otras fuentes, no para reemplazar aquellas, sino más bien para justificar que sea llenado ese vacío. La lógica indica que por su particular situación geográfica, histórica, social y cultural, el Soconusco albergue a la gente originaria de Centroamérica, más allá de los flujos más estudiados — trabajadores agrícolas temporales, refugiados guatemaltecos, migrantes en tránsito-; es decir, la presencia de los que se quedan - una presencia real, susceptible de ser documentada - no puede seguirse justificando a partir de los que se van y los que regresan forzados. No es posible que para evidenciar su presencia haya que mirar siempre las estadísticas de aseguramientos, expulsiones y deportaciones.

El trabajo etnográfico y las constantes visitas a algunos de los municipios de la región han permitido corroborar la presencia de centroamericanos, hombres, mujeres y menores de edad, que alimentan los distintos flujos identificados; pero también ha hecho posible evidenciar que la gente de Centroamérica se queda a vivir allí, aportando a la vida productiva, en tanto que se suman a los mercados laborales. Eso lo sabe la gente que vive en el lugar, los actores locales, pero no ha sido suficientemente explorado por los estudiosos de la frontera ni ha sido asumido por los agentes gubernamentales y los responsables de diseñar políticas públicas. La tarea de generación de información compete no solo al sector académico, que debiera mantener su interés en profundizar sobre los flujos migratorios ya estudiados y realizar estudios exploratorios entre los que menos se conoce, sino también a los tomadores de decisiones que debieran orientar políticas públicas que respondan a esa particular situación de Chiapas y, específicamente, del Soconusco. Por el momento, con las omisiones estadísticas - por mencionar solo uno de los problemas - se sigue invisibilizando a una parte significativa de la gente que habita esa comarca. De seguir así las cosas, los centroamericanos continuarán atrapados en esta paradoja de hacerse notar o bien cuando son expulsados del país o cuando son agredidos por la gente entre la que han hecho su vida ya desde hace décadas.

\section{Agradecimientos}

El autor desea agradecer a José Luis Escalona, de CIESASSureste, por haber dado el impulso para hacer realidad este texto, cuyas ideas fueron discutidas por vez primera con Carolina Rivera Farfán, de la misma institución, a quien se extiende el agradecimiento. Santiago Martínez Junco, profesor de la Universidad del Valle del Grijalva, en Tapachula, permitió el acceso a los centroamericanos que la organización civil Sin Fronteras apoya desde 2006 en los municipios de Mazatán y Huehuetán.

\section{Notas}

' Nótese acá el juego intencional de palabras: El gobierno del estado de Chiapas, presidido por Juan Sabines Guerrero, 2006-2012, ha impulsado una campaña con motivo de la anexión de la entidad a la federación mexicana bajo el lema "Chiapas, el estado más mexicano", campaña que ha sido utilizada también en la conmemoración del Bicentenario de la Independencia y Centenario del inicio de la Revolución Mexicana. Resulta interesante cómo dicho gobierno ha sabido explotar su estratégica posición geopolítica. Por un lado, el gobernador ha acompañado la política que el gobierno federal ha impulsado en la entidad y en el conjunto de la nación; por otro, se ha ganado la simpatía de los gobiernos centroamericanos, con los que ha estrechado lazos de amistad. El derrocado presidente de Honduras, José Manuel Zelaya, le impuso la Orden "José Cecilio del Valle", en grado de Gran Cruz Placa de Plata en 2008; ese mismo año, el gobierno guatemalteco, presidido por Álvaro Colom, lo nombró Embajador de la Paz, en un acto realizado en la ciudad de Comitán; finalmente, un año después, el gobierno salvadoreño 
hizo entrega, en la ciudad colonial de Chiapa de Corzo, de la Orden Nacional "José Matías Delgado" en el Grado Gran Cruz Placa de Plata, la máxima distinción que otorga El Salvador a los ciudadanos extranjeros. En los tres reconocimientos se mencionó el esfuerzo realizado por el actual gobierno de Chiapas en aras de garantizar el respeto de los derechos humanos de los migrantes centroamericanos que transitan por o residen en Chiapas.

${ }^{2}$ Quizá sea ocioso precisar lo que se entiende hoy por "Centroamérica", pero es pertinente hacerlo debido al devenir histórico de esta particular "comunidad económico-política", como se le llama en el Protocolo de Tegucigalpa, que dio origen en 1991 al Sistema de la Integración Centroamericana, SICA. Desde 1824, año en que también las elites chiapanecas decidieron anexionarse a México, queda constituida la "República Federal de Centro América”, formada por los nacientes estadosde Guatemala, Honduras, El Salvador, Nicaragua y Costa Rica, que fue la última en adherirse. Hasta muy entrado el siglo XX, "Centroamérica" se equiparó al conjunto de esas cinco naciones, que en 1951 habían formado la Organización de Estados Centroamericanos, ODECA. No obstante, en la actualidad, Belice y Panamá se incorporan a este conjunto regional, como miembros plenos de SICA. La actual "Centroamérica", pues, está compuesta por estos siete Estados y sus respectivos territorios y poblaciones.

${ }^{3}$ El INM, dependencia mexicana encargada de gestionar los movimientos migratorios en el país, utiliza el término "aseguramiento" en lugar de "detención" o "captura", para enfatizar que la migración irregular o indocumentada queda estipulada en la Ley General de Población - tras la enmienda y derogación de algunos artículos realizada en el año 2008- como una falta administrativa, mas no como un delito. "Aseguramiento" o "detención", lo cierto es que para los centroamericanos no hay mucha diferencia, una realidad expresada mediante la frase "me agarró la migra mexicana”.
${ }^{4}$ De más está decir que la "vida en frontera" no solo presupone el establecimiento de mecanismos institucionales y legales -aduanas, funcionarios, seguridad, recursos, leyes, revisiones, controles, cordones fitosanitarios, etcétera-, sino también la paulatina transferencia y asimilación de esos mecanismos en la sociedad, de modo que aquellos sean incorporados en los imaginarios colectivos e individuales.

${ }^{5}$ Eltratadopuedevisualizarseenelsiguientevínculo:http:// portal.sre.gob.mx/cilasur/pdf/tratadol882mexguat.pdf. ${ }^{6}$ La Forma Migratoria de Trabajador Fronterizo, FMTF, sustituye a la Forma Migratoria de Visitante Agrícola, FMVA, vigente desde 1997, y persigue documentar y ordenar los flujos de guatemaltecos y beliceños que pretenden desempeñarse como trabajadores fronterizos temporales en los estados de Chiapas, Tabasco, Campeche y Quintana Roo. El documento se comenzó a emitir en Ciudad Hidalgo hasta junio de 2009. En el poblado fronterizo de Talismán se ubica la llamada "Casa Roja", instalaciones que albergan la oficina local de INM, que por años ha sido el lugar de ingreso y documentación de los jornaleros agrícolas guatemaltecos.

7 Durante todo 2009, INM devolvió a sus países únicamente a 5 panameños, 18 costarricenses y 24 beliceños.

${ }^{8}$ El siguiente apartado se ilustra con estudios de caso de migrantes centroamericanos, mismos que fueron documentados entre septiembre de 2007 y enero de 2008, en el marco de la estancia de campo para sustentar la tesis de maestría titulada "Tejiendo redes frente al riesgo y la vulnerabilidad: Migrantes centroamericanos y organizaciones civiles de apoyo en Tapachula, Chiapas", defendida en CIESAS, unidad Sureste, en agosto de 2008.

9 Los centroamericanos asegurados y en proceso de deportación son trasladados a la Estación Migratoria Siglo XXI de Tapachula antes de ser repatriados a las fronteras de sus países. Allí se les puede entrevistar 
con ciertas restricciones - por ejemplo, sin grabadoras ni cámaras fotográficas-. Dado que los funcionarios de INM han reforzado las medidas de seguridad en el recinto, el acceso al mismo es restringido.

${ }^{10}$ La Ley General de Población faculta únicamente a los agentes del Instituto Nacional de Migración y a la Policía Federal para hacer verificaciones migratorias y aseguramientos; no obstante, en la práctica, cualquier autoridad no autorizada realiza esos procedimientos. Las más señaladas por violar la misma ley son las policías municipales y las estatales.

${ }^{11}$ Este grupo migratorio no habría sido cuantificado por las autoridades mexicanas - y esto no es una excusa - debido a que buena parte de él se interna en situación irregular y permanece así, además de ser un grupo en constante modificación por los nuevos ingresos, deportaciones y dinámica migratoria misma. No obstante, una investigación posterior puede tomar como base una cuantificación provisional de ese grupo a partir de las cifras de centroamericanos que se han acogido a cada programa anual de regularización migratoria del INM y que han obtenido un documento que ampare su estadía en México. Ello podría brindar una primera aproximación que no obstante sería incompleta, ya que solo nos daría luces sobre la población documentada, evidentemente minoritaria si se estima que la mayor parte de los centroamericanos viven en situación irregular en México.

12 Sería interesante realizar un estudio del impacto sicológico de los migrantes centroamericanos que se han quedado a vivir en alguna de las localidades del Soconusco, debido a que quedaron imposibilitados de proseguir su viaje. Aunque no siempre es así, en la prensa local - un ejemplo de ellos se lee en la nota subtitulada "Indigentes 'amueblan' su banqueta", publicada en Diario del Sur, Tapachula, 30 de junio de 2008) se relacionan muchos casos de enfermedades mentales con migrantes centroamericanos que se quedaron a vivir en la calle. En la prensa escrita se les tilda de locos, enajenados y sucios; en general, se les considera un problema social.

${ }^{13}$ En adelante se utilizan seudónimos.

${ }^{14}$ Entrevista, Mazatán, 9 de diciembre de 2007.

${ }^{15}$ De acuerdo con la Ley General de Población, artículo 44, "inmigrante es el extranjero que se interna legalmente en el país con el propósito de radicarse en él, en tanto adquiere la calidad de inmigrado". Dentro de la calidad de inmigrante caben las siguientes características: rentistas, inversionistas, profesional, cargos de confianza, científico, técnico, familiares, artistas y deportistas, y asimilados. Es de esperarse que casi la totalidad de los centroamericanos tienen la característica migratoria de asimilados. A partir de 2010, el FM2 es sustituido por la FMI, Forma Migratoria del Inmigrante, que tiene los mismos objetivos y está dirigida a la misma población.

${ }^{16}$ Las "volantas" son puntos de revisión improvisados resultante de operativos sorpresa por parte de agentes de INM, que se vienen a sumar a los puntos de revisión reconocidos oficialmente.

17 "Triciclero" es el conductor del "triciclo", un medio de transporte local que la gente utiliza para desplazarse o para llevar mercancías.

18 "Cámaras" son las balsas improvisadas por los lugareños en el río Suchiate para transportar personas y mercancías. Las fabrican de cámaras o neumáticos de tractor, sobre los que disponen plataformas de madera a manera de piso.

${ }^{19}$ En Guatemala y El Salvador "pisto" se refiere a dinero.

${ }^{20}$ Entrevista, Tapachula, 14 de septiembre de 2007.

21 La voz "vato" es utilizada por algunos jóvenes centroamericanos para referirse a personas ajenas al grupo social de adscripción. Entre las pandillas juveniles, por ejemplo, "vato" es alguien ajeno al grupo, no necesariamente de una pandilla rival.

${ }^{22}$ Se refiere a los que regresan repatriados o deportados a sus países de origen, ya sea que se hayan entregado voluntariamente o hayan sido asegurados por las autoridades mexicanas. Dado que la mayoría regresa en 
esta última condición, se utiliza el epíteto "forzados". Distintas casas de migrantes han reportado casos en que los migrantes centroamericanos se han entregado voluntariamente a las autoridades migratorias cuando ya han sido víctimas de recurrentes agresiones a lo largo del territorio mexicano.

${ }^{23}$ Dicho acuerdo tiene como antecedentes las reuniones del Grupo Binacional México-Guatemala, cuya primera sesión fue instalada en 1989. Data de 1992 el primer acuerdo de deportación de guatemaltecos y demás centroamericanos, un entendimiento que se realizó únicamente entre México y Guatemala. Diez años después, el 13 de junio de 2002, se firmó el "Arreglo para la Repatriación Segura y Ordenada de Extranjeros Centroamericanos en las Fronteras de México y Guatemala", que sirvió de base para el "Acuerdo entre la Secretaría de Gobernación de los Estados Unidos Mexicanos y el Ministerio de Gobernación de la República de Guatemala para la Repatriación Segura y Ordenada de Nacionales Guatemaltecos, Salvadoreños y Hondureños en las Fronteras de México y Guatemala", que entró en vigencia el 28 de junio de 2005 (Caso et al., 2006: 181). Este último fue sustituido por el "Memorándum de entendimiento entre los gobiernos de los Estados Unidos Mexicanos, de la República de El Salvador, de la República de Guatemala, de la República de Honduras y de la República de Nicaragua, para la repatriación digna, ordenada, ágil y segura de nacionales centroamericanos migrantes vía terrestre", suscrito el 5 de mayo de 2006 y su anexo de 26 de abril de 2007.

24 No se ha abundado en este artículo sobre la problemática centroamericana, que explicaría mucho de estos flujos migratorios. ¿Por qué emigra la gente de Centroamérica? ¿Se esperaría una disminución de los flujos en el mediano o largo plazo? Estos puntos rebasan la atención analítica de este artículo y también reclaman un trabajo detenido. Digamos de momento que aunque la emigración tiene múltiples causas, durante los últimos años, las situaciones de violencia e inseguridad pública en Centroamérica han cobrado relevancia a la hora de explicar los motivos por los que la gente abandona sus países.

${ }^{25}$ No siempre la migración es sinónimo de tragedia. En algunas ocasiones, los migrantes — sobre todo los más jóvenes- interpretan su proceso migratorio como una aventura y, hasta cierto punto, como algo lúdico. Detrás de esto subyacen, obviamente, una serie de elementos subjetivos que mueven a esa interpretación del proceso migratorio. Se es optimista, por ejemplo, frente a las adversidades, una característica común entre los migrantes centroamericanos. La reincidencia - cuando se ha sufrido muchos aseguramientos y deportacioneses consecuencia de la determinación mostrada por ellos: se llegará al lugar de destino cueste lo que cueste, tarde lo que tarde. Un migrante salvadoreño entrevistado en el Albergue Belén imprimía a su proceso migratorio una connotación de lucha: "iVencer o morir! Yo llegaré a Estados Unidos".

${ }^{26}$ Entrevista, Tapachula, 5 de noviembre de 2007.

${ }^{27}$ Entrevista, Tapachula, 5 de noviembre de 2007.

\section{Bibliografía}

Arriola, Aura (1995), Tapachula, "La Perla del Soconusco", ciudad estratégica para la redefinición de las fronteras, Guatemala: FLACSO.

Bourdieu, Pierre (1997), Razones prácticas: Sobre la teoría de la acción, Barcelona: Anagrama.

Bourdieu, Pierre (1990), Outline of a Theory of Practice, Cambridge: Cambridge University Press.

Bourdieu, Pierre y Wacquant Loïc J.D. (1995), Respuestas por una antropología reflexiva, México: Grijalbo.

Casillas, Rodolfo (2007), Una vida discreta, fugaz y anónima. Los centroamericanos transmigrantes en México, México: $\mathrm{OIM} / \mathrm{CNDH}$.

Casillas, Rodolfo (1996), “Un viaje más allá de la frontera: los migrantes centroamericanos en México", en Perfiles Latinoamericanos, año/vol.5, núm. 8, México: FLACSO, pp. 141-171. 
Caso, Agustín, et al. (2006), Migración y repatriaciones. México en la encrucijada norte sur, México: Rosa María Porrúa Ediciones.

Castillo, Manuel A. (2003), "Los desafíos de la emigración centroamericana en el Siglo XXI", en Amérique Latine Histoire et Mémoire, núm. 7, Migrations Etats-Unis Mexique terre d'accueil, http://alhim.revues.org/document369. html [Consultado, 4 de mayo de 2010].

Castillo, Manuel A. (2002), "Región y frontera: la frontera sur de México”, en Kauffer, Edith F. (Edit.) Identidades, migraciones y género en la frontera sur de México, San Cristóbal de las Casas: ECOSUR, pp. 19-47.

De Vos, Jan (2005), "La formación de la frontera entre México y Centroamérica”, en Hernández, Salvador (coord.), Frontera sur de México: cinco formas de interacción entre sociedad y ambiente, México: ECOSUR, pp. 15-20.

De Vos, Jan (2002), "La frontera sur y sus fronteras: una visión histórica”, en Kauffer, Edith F. (Edit.) Identidades, migraciones y género en la frontera sur de México, San Cristóbal de las Casas, ECOSUR, pp. 49-67.

Instituto Nacional de Migración (INM) et al. (2006), Encuesta sobre Migración en la Frontera Guatemala-México 2004, México: INM/CONAPO/COLEF/SEGOB/ STPS/SER.

Instituto para la Seguridad y la Democracia (INSYDE) (2008), Percepciones sobre la migración en la frontera sur. Encuesta en vivienda. http://www.insyde.org.mx/ images/reporte $\% 20$ percepciones $\% 20$ sobre $\% 20$ la\%20migración\%20en\%20la\%20frontera\%20sur. pdf, [8 de noviembre de 2010].

Kauffer, Edith F. (2005a), "De la frontera política a las fronteras étnicas. Refugiados guatemaltecos en México", en Frontera Norte, vol. 17, núm. 34, (juliodiciembre), Tijuana, México: COLEF, pp. 7-36.
Kauffer, Edith F.(2005b), "El paradigma dela repatriación a la prueba de los hechos: elementos para entender la nueva migración de los ex refugiados guatemaltecos a México", en Ángeles, Hugo, et al (coords.), Actoresy realidadesen la Frontera Sur de México, México: COESPOChiapas/ECOSUR, pp. 191-215.

Kauffer, Edith F. (2002), "Movimientos migratorios forzosos en la frontera sur: una visión comparativa de los refugiados guatemaltecos en el sureste mexicano", en Kauffer, Edith F. (editora), Identidades, migraciones y género en la frontera sur de México, San Cristóbal de las Casas: ECOSUR, pp. 215-242.

Larraínzar, Manuel (1996) [1843], Chiapas y Soconusco. La cuestión de límites entre México y Guatemala, México: CONECULTA/UNICACH.

Long, Norman (2007), Sociología del desarrollo. Una perspectiva centrada en el actor, México: COLSAN/ CIESAS.

Pineda, Emeterio (1999) [1845], Descripción geográfica del departamento de Chiapas y Soconusco, México: CONECULTA/FCE.

Rivas, Jaime (2008), Tejiendo redes frente al riesgo y la vulnerabilidad. Migrantes centroamericanos y organizaciones civiles de apoyo en Tapachula, Chiapas, Tesis de maestría en Antropología Social, San Cristóbal de las Casas, México: CIESAS.

Rojas, Martha y Ángeles, Hugo (2003), "La frontera de Chiapas con Guatemala como destino de migrantes internacionales", en Ecofronteras, núm. 19, (agosto), México: ECOSUR, pp. 15-17.

Villafuerte, Daniel (2008), "El Soconusco: la Frontera de la Frontera Sur”, en Sánchez, José, Jarquín, Ramón (Coords.), La frontera sur. Reflexiones sobre el Soconusco, Chiapas y sus problemas ambientales, poblacionales y productivos, México: Senado de la República/ ECOSUR, pp. 157-168. 
Cuadro 1. Trabajadores temporales guatemaltecos documentados con FMVA, 1999-2007

\begin{tabular}{|l||c|}
\hline \multicolumn{1}{|c||}{ Año } & Cantidad \\
\hline \hline 1999 & 64,961 \\
\hline \hline 2000 & 69,036 \\
\hline \hline 2001 & 40,640 \\
\hline \hline 2002 & 38,693 \\
\hline 2003 & 45,561 \\
\hline 2004 & 42,895 \\
\hline 2005 & 45,518 \\
\hline \hline 2006 & 40,244 \\
\hline \hline 2007 & 27,840 \\
\hline \hline Total & $\mathbf{4 1 5 , 3 8 8}$ \\
\hline
\end{tabular}

Fuente: Elaboración propia con base en estadísticas del Instituto Nacional de Migración, INM

Cuadro 1. Una década de contención de los flujos migratorios. Eventos de aseguramiento de centroamericanos indocumentados en México según nacionalidad, 1999-2009

\begin{tabular}{|c|c|c|c|c|c|c|c|c|c|c|c|}
\hline \multirow[t]{2}{*}{ Año } & \multicolumn{2}{|c|}{ Guatemala } & \multicolumn{2}{|c|}{ Honduras } & \multicolumn{2}{|c|}{ El Salvador } & \multicolumn{2}{|c|}{ Nicaragua } & \multicolumn{2}{|c|}{$\begin{array}{c}\text { Países } \\
\text { seleccionados }\end{array}$} & \multirow[t]{2}{*}{$\begin{array}{l}\text { Total } \\
\text { países }\end{array}$} \\
\hline & Cantidad & $\%$ & Cantidad & $\%$ & Cantidad & $\%$ & Cantidad & $\%$ & Cantidad & $\%$ & \\
\hline 1999 & 50,228 & 40.1 & 43,805 & 34.9 & 26,110 & 20.8 & 1,387 & 1.1 & 121,530 & 96.9 & 125,238 \\
\hline 2000 & 78,819 & 48.7 & 45,604 & 28.2 & 37,203 & 23.0 & 1,938 & 1.2 & 161,626 & 95.7 & 168,765 \\
\hline 2001 & 67,522 & 46.8 & 40,105 & 27.8 & 35,007 & 24.3 & 1,712 & 1.2 & 144,346 & 95.9 & 150,530 \\
\hline 2002 & 67,336 & 51.2 & 41,801 & 31.8 & 20,800 & 15.8 & 1,609 & 1.2 & 131,546 & 95.3 & 138,061 \\
\hline 2003 & 86,023 & 48.0 & 61,900 & 34.5 & 29,301 & 16.3 & 2,150 & 1.2 & 179,374 & 95.6 & 187,614 \\
\hline 2004 & 94,404 & 43.8 & 72,684 & 33.7 & 34,572 & 16.0 & 2,453 & 1.1 & 204,113 & 94.6 & 215,695 \\
\hline 2005 & 100,948 & 42.0 & 78,326 & 32.6 & 42,674 & 17.8 & 3,980 & 1.6 & 225,928 & 94.0 & 240,269 \\
\hline 2006 & 84,523 & 46.3 & 58,001 & 31.7 & 27,287 & 14.9 & 3,590 & 2.0 & 173,401 & 94.9 & 182,705 \\
\hline 2007(a) & 68,537 & 41.5 & 60,324 & 36.5 & 22,141 & 13.4 & 3,225 & 1.9 & 154,227 & 93.3 & 165,134 \\
\hline 2008(b) & 40,843 & 45.9 & 29,654 & 33.3 & 13,708 & 15.4 & 1,526 & 1.7 & 85,731 & 96.3 & $88,955(c)$ \\
\hline 2009(d) & 25,059 & 44.7 & 20,141 & 35.9 & 8,580 & 15.3 & 722 & 1.3 & 54,502 & 97.2 & 56,043 \\
\hline
\end{tabular}

Fuente: Elaboración propia con base en estadísticas del Instituto Nacional de Migración, INM.

(a) Para realizar un comparativo con los datos de años anteriores a 2007 se deben sumar en este año las estadísticas de eventos de aseguramiento, con los de repatriaciones voluntarias — solo de centroamericanos - y expulsiones realizados por la autoridad migratoria.

(b) A partir de 2008 la serie estadística únicamente desglosa por nacionalidad los eventos de expulsión del país y repatriación voluntaria de centroamericanos, quedando los eventos de aseguramiento desglosados por sexo, edad y delegación regional.

(c) La cifra no incluye el total de eventos de aseguramiento, que ascendió a 39,330 en ese año; es decir, no conocemos las nacionalidades de las personas aseguradas en 2008. De este modo, los eventos de expulsión, repatriación y aseguramiento arrojan una suma total de 128,285.

(d) Se refiere a eventos de expulsión de extranjeros, repatriación de centroamericanos y devolución de menores a sus países de origen. No incluye aseguramientos.

Revista LiminaR. Estudios sociales y humanísticos, año 8, vol. VIII, núm. 2, diciembre de 2010, San Cristóbal de Las Casas, Chiapas, México. ISSN: 1665-8027 
Mapa 1. El Soconusco en el estado de Chiapas

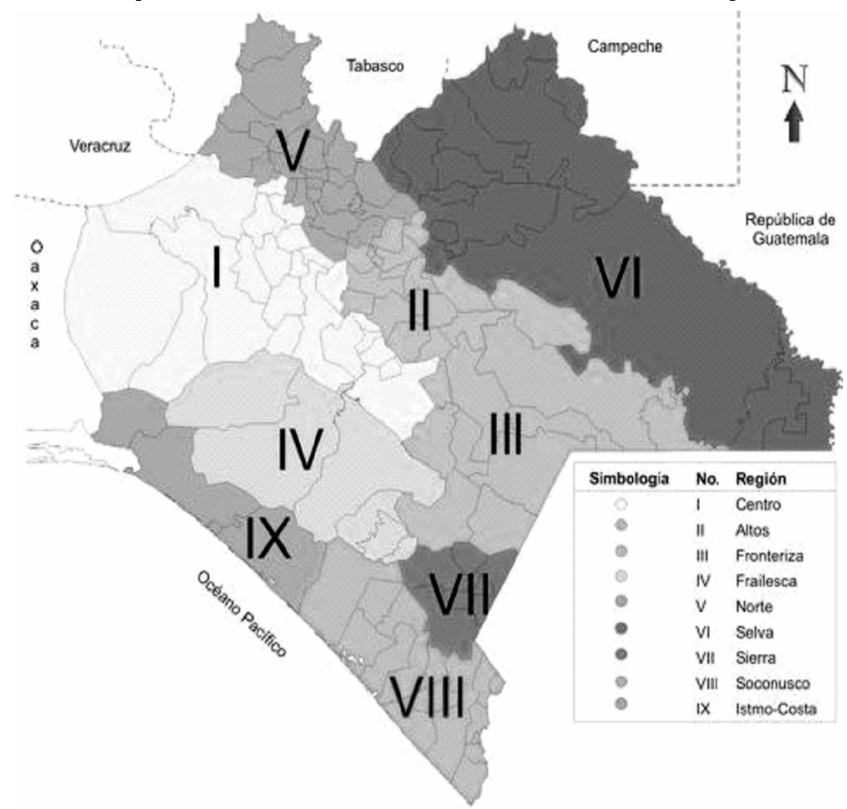

Fuente: http://www.e-local.gob.mx/work/templates/enciclo/chiapas/pres.htm\#est

Mapa 2. Chiapas: Región VII. Soconusco y sus municipios

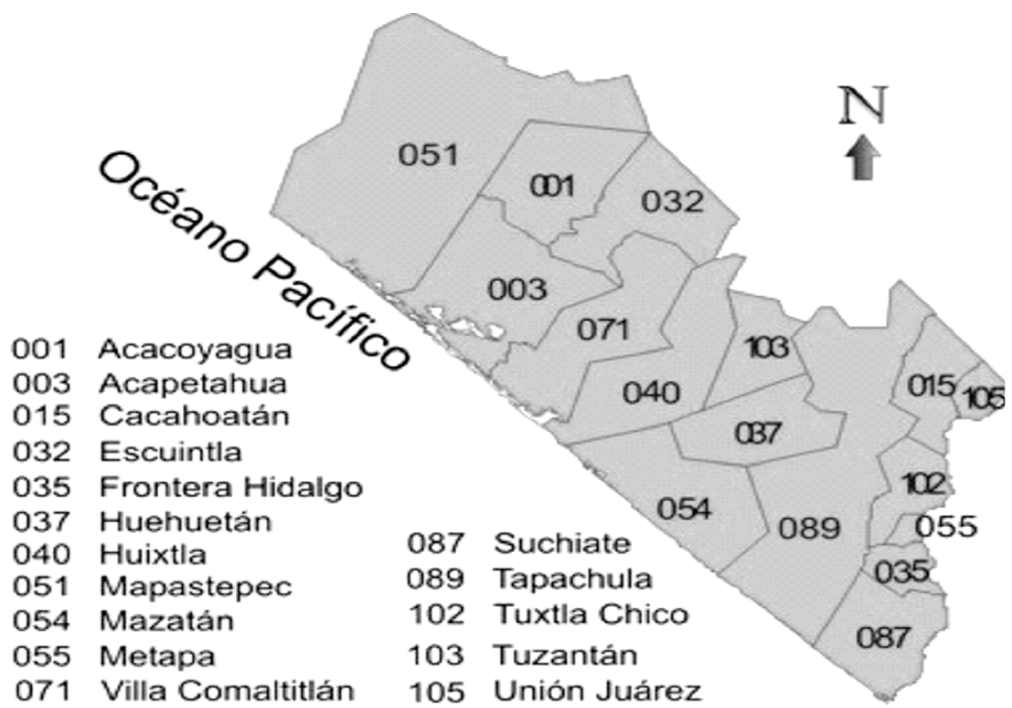

Fuente: http://www.e-local.gob.mx/work/templates/enciclo/chiapas/regiones.htmlłkr8 